\title{
FAKTOR-FAKTOR YANG DIANGGAP SEBAGAI PREDIKTOR TERHADAP KEEFEKTIFAN KELOMPOK TUTORIAL PROBLEM BASED LEARNING (PBL)
}

\author{
Yani Istadi*, Harsono** dan Yayi Suryo Prabandari** \\ *Fakultas Kedokteran Universitas Islam Sultan Agung, Semarang \\ **Fakultas Kedokteran Universitas Gadjah Mada, Yogyakarta
}

\begin{abstract}
Background: The tutorial plays a central role in problem-based learning (PBL). The effectiveness of small group tutorials is one of the key aspects to the students' success in exam. This study aimed to identify factors perceived as the predictors for effectiveness of PBL tutorial group.

Method: The subjects of the study were all of the students (year of 2008) of the Medical College of Sultan Agung Islamic University who were taking tropical disease module. The adapted version of the scales adopted in this study included the scale developed by Van den Bossche et al. for assessing team effectiveness, beliefs about the interpersonal context and group's learning behavior dimension, scale developed by Dolmans E Ginns for assessing tutor's performance, scale developed by Munshi et al. for assessing quality of case problem, scale developed by Lepper et al. for assessing learning motivation. Quantitative approach with correlation and double regression analysis was applied.

Results: The 223 subject included in the study consisting of 84 (37.3\%) male and 139 (62.3\%) female students. There was a significant correlation between effectiveness of tutorial group and a tutor's performance $(r=0.456, p<0.01)$, quality of case problem $(r=0.366, p<0.01)$, beliefs about the interpersonal context dimension $(r=0.631, p<0.01)$, group's learning behavior $(r=0.559, p<0.01)$ and motivation $(r=0.137, p<0.05)$. There was a correlation between the variables of tutor's performance, beliefs about the interpersonal context dimension, and learning behavior and group effectiveness indicated by the regression coefficient of $0.739(p<0.05)$. These three variables contributed to the group effectiveness as much as $54 \%$ with $F$ value 87.857 . The quality of case problem and motivations were not the predictive factors for group effectiveness.

Conclusion: Improving tutorial group effectiveness requires improving factors beliefs about the interpersonal context dimension, group's learning behaviors dimension and tutor's performance. A favorable learning atmosphere is needed to improved motivation and better quality of case problem.
\end{abstract}

Keywords: tutor's performance, quality of case problem, beliefs about the interpersonal context dimension, group's learning behavior dimension, learning behavior, motivation, group effectiveness

\section{ABSTRAK}

Latar Belakang: Problem based Learning (PBL) merupakan salah satu pendekatan pendidikan berbasis kelompok dan kolaboratif. Tutorial merupakan jantungnya PBL (Mclean et al., 2006). Keefektifan kelompok tutorial merupakan salah satu poin penting dalam mengantarkan mahasiswa untuk sukses ujian. Penelitian ini bertujuan untuk mengidentifikasi faktor-faktor yang dianggap sebagai prediktor terhadap keefektifan kelompok tutorial PBL.

Metode: Seluruh mahasiswa angkatan 2008 Fakultas Kedokteran UNISSULA yang mengikuti modul penyakit tropis menjadi subjek dalam penelitian ini. Skala yang digunakanmerupakan hasil adaptasi, diantaranya keefektifan kelompok, dimensi kepercayaan dan perilaku belajar kelompok dari Van den Bossche et al, kinerja tutor dari Dolmans dan Ginns, kualitas masalah dari Munshi et al. dan motivasi belajar dikembangkan dari skala motivasi belajar milik Lepper et al. Penelitian dilakukan dengan metode kuantitatif dan dianalisis dengan korelasi dan regresi berganda.

\footnotetext{
Korespondensi: bosse-fk@yahoo.co.id

FK UNISULA JI. Raya Kaligawe KM4 Semarang 50112 Fax: 024-6594366
} 
Hasil: Subjek yang terlibat berjumlah 223 yang terdiri dari laki-laki sebanyak 84 orang $(37,7 \%)$ dan wanita sebanyak 139 orang $(62,3 \%)$. Ada hubungan positif dan signifikan antara keefektifan kelompok dengan kinerja tutor $(r=0.456$ dengan $\mathrm{p}<0,01)$, kualitas masalah $(\mathrm{r}=0,366$ dengan $\mathrm{p}<0,01)$ dimensi kepercayaan tentang hubungan di antara anggota-anggota kelompok $(r=0,631$ dengan $\mathrm{p}<0,01)$, perilaku belajar kelompok $(\mathrm{r}=0,559$ dengan $\mathrm{p}<0,01)$, dan motivasi $(r=0,137$ dengan $p<0,05)$. Terdapat hubungan secara bersama-sama antara kinerja tutor, dimensi kepercayaan tentang hubungan di antara anggota-anggota kelompok, dan perilaku belajar kelompok dengan keefektifan kelompok, dengan nilai koefisien regresi $(R)$ sebesar 0,739 dengan $p<0,05$, sumbangan efektif ketiga variabel tersebut secara bersama-sama sebesar $54 \%$ dengan nilai $\mathrm{F}$ sebesar 87,857 . Kualitas masalah dan motivasi merupakan faktor prediksi terhadap keefektifan kelompok.

Kesimpulan: Untuk meningkatkan keefektifan kelompok tutorial, faktor kepercayaan tentang hubungan di antara anggota-anggota kelompok, perilaku belajar kelompok dan kinerja tutor perlu ditingkatkan. Perlu diciptakan suasana belajar yang dapat meningkatkan motivasi dan perbaikan terhadap kualitas masalah dalam skenario.

Kata kunci: kinerja tutor, kualitas masalah, dimensi kepercayaan, perilaku belajar,motivasi, keefektifan kelompok

\section{PENDAHULUAN}

Problem based learning (PBL) merupakan salah satu pendekatan pendidikan berbasis kelompok dan kolaboratif. Pendekatan ini digunakan untuk meningkatkan konstruksi aktif dan aplikasi pengetahuan secara integratif; keterampilan belajar kelompok seperti kemampuan untuk berkomunikasi efektif, menentukan prioritas pekerjaan/tugas, mengatur waktu dan melatih keterampilan interpersonal; dan profesionalisme. ${ }^{1,2}$ Oleh karena itu, berbagai negara memilih menggunakan model pendekatan ini sebagai metode pembelajaran, terutama pendidikan kedokteran. Namun, dalam pelaksanaan disesuaikan dengan lingkungan pendidikan yang mereka punyai.

Kelompok dalam PBL adalah kelompok diskusi kecil (small group discussion (SGD) yang terdiri dari 10-12 orang difasilitasi oleh seorang tutor dan menggunakan masalah yang diangkat dari fenomena atau kejadian-kejadian di sekitar sebagai pencetus diskusi. Belajar dalam kelompok kecil mempunyai beberapa manfaat, diantaranya: (1) mendorong siswa untuk belajar aktif dan mandiri, sehingga dapat menimbulkan kesadaran belajar sepanjang hayat, (2) meningkatkan motivasi dan belajar siswa secara efisien melalui keterlibatannya didalam proses belajar, (3) menggali pemikiran siswa melalui hipotesis-hipotesis, (4) mendorong siswa untuk belajar mendalam (deep learning) dan meningkatkan level proses berpikir, (5) meningkatkan rasa tanggung jawab siswa berkaitan dengan profesi, dan (6) meningkatkan keterampilan seperti interpersonal, kepemimpinan, organisasi, memprioritaskan suatu masalah, mengatasi masalah, dan manajemen waktu. ${ }^{1}$ Manfaat tersebut akan dapat diperoleh jika kelompok tersebut dilaksanakan secara efektif.

Secara empirik, keefektifan kelompok merupakan salah satu poin penting kesuksesan mahasiswa dalam menempuh ujian. Hal ini telah diteliti oleh Schmidt \& Moust $^{18}$ dan Van Berkel \& Schmidt ${ }^{3}$ yang hasilnya menunjukkan ada hubungan yang positif pada kedua variabel tersebut. Mempertimbangkan manfaat keefektifan kelompok terhadap mahasiswa, institusi pendidikan kedokteran harus memastikan bahwa keefektifan kelompok dapat terwujud.

Pada saat ini sudah banyak penelitian tentang faktorfaktor yang berpengaruh terhadap keefektifan kelompok, diantaranya: (1) Schmidt \& Moust, Schmidt dan Schmidt $\&$ Moust ${ }^{4,5,6}$ meneliti tentang besaran pengetahuan mahasiswa sebelumnya (prior knowledge), kualitas skenario dan kinerja tutor, (2) Dolmans et al meneliti faktor dimensi motivasi dan kognitif, dan (3) Van den Bossche et $a l^{8}$ meneliti faktor dimensi kepercayaan tentang hubungan antar anggota dalam kelompok dan perilaku belajar kelompok. Namun demikian, belum diteliti seberapa besar pengaruh faktor-faktor tersebut dapat memprediksi keefektifan kelompok, sehingga faktorfaktor tersebut dapat diidentifikasi agar dapat ditingkatkan dan diperbaiki.

Penelitian ini bertujuan untuk mengidentifikasi faktorfaktor yang menjadi prediktor terhadap keefektifan kelompok tutorial PBL. 


\section{METODE}

Subjek penelitian ini adalah semua mahasiswa angkatan Subjek penelitian ini adalah semua mahasiswa angkatan 2008 Fakultas Kedokteran Universitas Islam Sultan Agung Semarang semester 4 yang mengambil modul penyakit tropis. Instrumen penelitian yang digunakan merupakan hasil adaptasi dari instrumen penelitian keefektifan kelompok, dimensi kepercayaan dan perilaku belajar kelompok dari Van den Bossche et al, ${ }^{8}$ kinerja tutor dari Dolmans \& Ginns ${ }^{9}$, kualitas masalah dari Munshi et al ${ }^{10}$ dan motivasi belajar yang dikembangkan dari skala motivasi belajar milik Lepper et all dengan beberapa penambahan item baru yang disesuaikan dalam konteks kegiatan tutorial. Instrumen penelitian yang dibuat dikelompokkan dalam 6 skala. Respon dari instrumen penelitian ini menggunakan 5 pilihan berdasarkan model Likert. Skor angka 5 untuk respon sangat setuju sekali hingga angka 1 untuk respon sangat tidak setuju. Instrumen penelitian yang digunakan sudah diujicoba dan memenuhi persyaratan dengan keseluruhan butir instrumen memiliki koefisien validitas $\mathrm{r}_{\mathrm{ix}} \mathrm{e}$ " 0,3 dan memiliki nilai Alpha Cronbach e" 0,70.

Modul penyakit tropis merupakan modul kedua setelah modul enterohepatik pada semester 4, yang dilaksanakan selama 4 minggu. Metode pembelajaran yang digunakan adalah tutorial, kuliah pakar, keterampilan medik, belajar mandiri, dan panel ahli. Tutorial dilaksanakan seminggu 2 kali, dengan interval waktu 2 hari. Masing-masing pertemuan dilaksanakan selama 2 jam. Empat scenario digunakan untuk memicu diskusi. Diskusi tutorial menggunakan metode 7 langkah. Kelompok tutorial yang terlibat dalam modul penyakit tropis berjumlah 20. Setiap kelompok terdiri dari 11 - 12 mahasiswa (n 238) yang difasilitasi oleh satu orang tutor $(n=20)$. Setelah pelaksanaan modul penyakit tropis selesai, mahasiswa diminta untukmengisi kuesioner yang sudah disiapkan dengan terlebih dahulu mengisi surat persetujuan (informed consent).

Selama pengisian kuesioner, peneliti membantu mahasiswa untuk memahami maksud kalimat-kalimat dalam kuesioner dengan memberikan penjelasan tambahan, selanjutnya mahasiswa dipersilakan memilih jawaban tanpa intervensi dari peneliti. Informed concent kepada responden diberikan secara tertulis dalam kuesioner dan secara lisan pada saat peneliti memberikan penjelasan sebelum pengisian kuesioner.

Keseluruhan data dianalisis dengan menggunakan perangkat lunak statistik. Uji statistik yang dilakukan adalah uji korelasi dan uji regresi berganda dengan terlebih dahulu melakukan uji asumsi, yaitu uji normalitas data dan uji linieritas regresi. Penelitian ini telah disetujui oleh Komite Etik Fakultas Kedokteran, Universitas Gadjah Mada, Yogyakarta.

\section{HASIL DAN PEMBAHASAN}

Sejumlah 238 mahasiswa berpartisipasi dalam penelitian ini. Setelah data dikumpulkan, 15 mahasiswa dikeluarkan karena tidak mengisi kuesioner dengan lengkap, sehingga hanya 223 mahasiswa yang diikutkan dalam analisis data yang terdiri dari 84 orang $(37,7 \%)$ laki-laki dan 139 orang $(62,3 \%)$ wanita.

Untuk mengidentifikasi adanya hubungan yang positif dan significancy antara kinerja tutor, kualitas masalah, dimensi kepercayaan hubungan antar anggota dalam kelompok, dimensi perilaku belajar kelompok, dan motivasi dengan keefektifan kelompok, digunakan analisis korelasi. Analisis ini dimulai dengan uji normalitas yang mendapatkan bahwa sebaran data dari keenam skala berdistribusi tidak normal (Tabel 1).

Tabel 1. Hasil analisis uji normalitas $(\mathrm{n}=223)$

\begin{tabular}{llcccccc} 
& & \multicolumn{4}{c}{ Std } & \multicolumn{3}{c}{ Kolmogorov-Smirnov $^{\text {a }}$} \\
& & Mean & deviasi & Statistic & df & Sig. & P-value \\
\hline 1 & Kinerja tutor & 39,2197 & 5,30011 &, 100 & 223 &, 000 & $<0,05$ \\
2 & Kualitas masalah & 65,9686 & 6,55908 &, 086 & 223 &, 000 & $<0,05$ \\
3 & Kepercayaan hubungan & 63,8027 & 7,23770 &, 094 & 223 &, 000 & $<0,05$ \\
4 & Perilaku belajar kelompok & 34,5605 & 4,17356 &, 115 & 223 &, 000 & $<0,05$ \\
5 & Motivasi & 46,5202 & 8,05881 &, 072 & 223 &, 006 & $<0,05$ \\
6 & Keefektifan kelompok & 23,0179 & 3,22290 &, 144 & 223 &, 000 & $<0,05$ \\
\hline
\end{tabular}


Kemudian dilanjutkan dengan analisis korelasi menggunakan teknik Spearman Rank yang hasilnya menunjukkan semua variabel bebas, yaitu kinerja tutor, kualitas masalah, dimensi kepercayaan hubungan antar anggota dalam kelompok, dimensi perilaku belajar kelompok, dan motivasi mempunyai hubungan positif dan signifikan dengan keefektifan kelompok. Artinya, semakin tinggi kinerja tutor, kualitas masalah, dimensi kepercayaan hubungan antar anggota dalam kelompok, dimensi perilaku belajar kelompok, dan motivasi, semakin tinggi keefektifan kelompok. Variabel motivasi memiliki tingkat hubungan yang sangat rendah terhadap semua variabel penelitian ini, sedangkan dimensi kepercayaan hubungan antar anggota dalam kelompok memiliki tingkat hubungan yang kuat dengan keefektifan kelompok jika dibandingkan dengan variabel lainnya (Tabel 2).

Tabel 2. Hasil interkorelasi Sperman Rank $(\mathrm{n}=223)$

\begin{tabular}{|c|c|c|c|c|c|c|c|}
\hline & & 1 & 2 & 3 & 4 & 5 & 6 \\
\hline 1 & Kinerja tutor & - & & & & & \\
\hline 2 & Kualitas masalah &, $\left.5311^{* *}\right)$ & - & & & & \\
\hline 3 & Kepercayaan hubungan &, $\left.420{ }^{* *}\right)$ &, $\left.365^{* *}\right)$ & - & & & \\
\hline 4 & Perilaku belajar kelompok &, $\left.456^{* *}\right)$ &, $374\left(^{* *}\right)$ &, $\left.666^{* *}\right)$ & - & & \\
\hline 5 & Motivasi &, $168\left(^{*}\right)$ &, $260\left(^{* *}\right)$ &, $161\left(^{*}\right)$ &, $198\left(^{* *}\right)$ & - & \\
\hline 6 & Keefektifan kelompok &, $456\left(^{* *}\right)$ &, $366\left(^{* *}\right)$ &, $631\left(^{* *}\right)$ &, $\left.559{ }^{* *}\right)$ &, $137\left(^{*}\right)$ & - \\
\hline
\end{tabular}

Untuk mengidentifikasi faktor-faktor prediktor yang berpengaruh terhadap keefektifan kelompok tutorial PBL, digunakan analisis regresi berganda, yang sebelumnya dilakukan uji linieritas (uji F). ${ }^{12}$ Hasil uji menunjukkan bahwa kinerja tutor, kualitas masalah, dimensi kepercayaan hubungan antar anggota dalam kelompok dan dimensi perilaku belajar kelompok mempunyai arah regresi linier dan signifikan sedangkan motivasi tidak menunjukkan linieritas sehingga variabel motivasi selanjutnya tidak dimasukkan dalam model regresi (Tabel 3).

Tabel 3. Hasil uji linieritas regresi $(n=223)$

\begin{tabular}{|c|c|c|c|c|c|}
\hline & \multirow[t]{2}{*}{ F (hitung) } & \multicolumn{2}{|c|}{ F (tabel) } & \multirow[t]{2}{*}{ Sig. } & \multirow[t]{2}{*}{ Keterangan } \\
\hline & & $\begin{array}{l}\text { Batas } \\
\text { atas } 5 \%\end{array}$ & $\begin{array}{c}\text { Batas } \\
\text { bawah } \\
1 \%\end{array}$ & & \\
\hline $\begin{array}{l}\text { Kinerja tutor terhadap } \\
\text { keefektifan kelompok }\end{array}$ & 70,620 & 3,89 & 6,76 & 0,000 & $\begin{array}{l}\text { nilai } F(\text { hitung })>\text { nilai } \\
F(\text { tabel) maka arah regresi } \\
\text { linier dan signifikan }\end{array}$ \\
\hline $\begin{array}{l}\text { Kualitas masalah terhadap } \\
\text { keefektifan kelompok }\end{array}$ & 48,696 & 3,89 & 6,76 & 0,000 & $\begin{array}{l}\text { nilai } F(\text { hitung) }>\text { nilai } \\
F(\text { tabel) maka arah regresi } \\
\text { linier dan sionifikan }\end{array}$ \\
\hline $\begin{array}{l}\text { Kepercayaan hubungan } \\
\text { antar anggota dalam } \\
\text { kelompok terhadap } \\
\text { keefektifan kelompok }\end{array}$ & 211,388 & 3,89 & 6,76 & 0,000 & $\begin{array}{l}\text { nilai } F(\text { hitung) }>\text { nilai } \\
F(\text { tabel) maka arah regresi } \\
\text { linier dan signifikan }\end{array}$ \\
\hline $\begin{array}{l}\text { Skala perilaku belajar } \\
\text { kelompok terhadap }\end{array}$ & 132,866 & 3,89 & 6,76 & 0,000 & $\begin{array}{l}\text { nilai } F(\text { hitung })>\text { nilai } \\
\mathrm{F}(\text { tabel }) \text { maka arah regresi }\end{array}$ \\
\hline $\begin{array}{l}\text { keefektifan kelompok } \\
\text { Skala motivasi terhadap } \\
\text { keefektifan kelompok }\end{array}$ & 3,276 & 3,89 & 6,76 & 0,072 & $\begin{array}{l}\text { linier dan signifikan } \\
\text { nilai } F(\text { hitung) }<\text { nilai } \\
\text { F(tabel) maka arah regresi } \\
\text { tidak linier dan signifikan }\end{array}$ \\
\hline
\end{tabular}


Selanjutnya, dilakukan analisis dengan teknik regresi berganda dengan metode Stepwise. Hasilnya menunjukkan bahwa proses analisis dilakukan 3 tahạp, dengan setiap tahapan ada variabel yang dimasukkan dan dikeluarkan dalam model untuk mencari variabel prediktor yang kuat. Dari tahapan tersebut didapatkan model 3 yang merupakan model akhir yang dapat memprediksi keefektifan kelompok. Semakin tinggi $\mathrm{R}$ akan semakin baik bagi model regresi, karena variabel bebas dapat menjelaskan variabel tergantung lebih besar ${ }^{13}$ dan uji $\mathrm{F}$ sebesar 87,857 yang memiliki tingkat signifikansi 0,000 (Tabel 4).

Tabel 4. Hasil model regresi metode Stepwise

\begin{tabular}{|c|c|c|c|c|c|c|c|c|}
\hline Model & & B & $\mathrm{t}$ & Sig. & $\mathrm{R}$ & $\begin{array}{l}\text { Adjusted } \\
\text { R Square }\end{array}$ & $\mathrm{F}$ & Sig \\
\hline \multirow[t]{2}{*}{1} & (Constant) & 3,153 & 2,293 & ,023 & \multirow[t]{2}{*}{,699 } & \multirow[t]{2}{*}{,487 } & \multirow[t]{2}{*}{211,388} & \multirow[t]{2}{*}{,000 } \\
\hline & $\begin{array}{l}\text { kepercayaan } \\
\text { hubungan }\end{array}$ & ,311 & 14,539 & ,000 & & & & \\
\hline \multirow[t]{3}{*}{2} & $($ Constant) & 1,209 & ,857 & ,392 & \multirow[t]{3}{*}{, 725} & \multirow[t]{3}{*}{, 521} & \multirow[t]{3}{*}{121,742} & \multirow[t]{3}{*}{,000 } \\
\hline & $\begin{array}{l}\text { kepercayaan } \\
\text { hubungan }\end{array}$ &, 234 & 8,334 & ,000 & & & & \\
\hline & $\begin{array}{l}\text { perilaku belajar } \\
\text { kelompok }\end{array}$ & ,200 & 4,110 &, 000 & & & & \\
\hline \multirow[t]{4}{*}{3} & (Constant) &,- 193 &,- 133 & ,894 & \multirow[t]{4}{*}{,739 } & \multirow[t]{4}{*}{, 540} & \multirow[t]{4}{*}{87,857} & \multirow[t]{4}{*}{,000 } \\
\hline & $\begin{array}{l}\text { kepercayaan } \\
\text { hubungan }\end{array}$ & ,215 & 7,645 & ,000 & & & & \\
\hline & $\begin{array}{l}\text { perilaku belajar } \\
\text { kelompok }\end{array}$ & , 158 & 3,208 & ,002 & & & & \\
\hline & kinerja tutor & ,103 & 3,172 &, 002 & & & & \\
\hline
\end{tabular}

Berdasar Tabel 4, maka model 3 memiliki pengaruh sebesar 54\% (Adjusted $R$ Square: 0,540) terhadap keefektifan kelompok, sedangkan 46\% dipengaruhi oleh variabel lain. Dengan demikian, berarti keefektifan kelompok tutorial lebih besar dipengaruhi oleh kinerja tutor, kepercayaan hubungan antar anggota dalam kelompok, dan perilaku belajar kelompok daripada variabel lain diluar dari model regresi ini.

Persamaan regresi berganda mendapatkan ó $=-, 193+$ $0,103 x_{1}+0,215 x_{2}+0,158 x_{3}$ Persamaan tersebut mempunyai arti jika variabel kinerja tutor, dimensi kepercayaan hubungan antar anggota dalam kelompok, dan perilaku belajar kelompok nilainya 0 , maka keefektifan kelompok nilainya negatif sebesar -0,193. Setiap penambahan (karena tanda + ) sebesar 1 , maka kinerja tutor, dimensi kepercayaan hubungan antar anggota dalam kelompok, dan dimensi perilaku belajar kelompok masing-masing akan meningkatkan keefektifan kelompok sebesar 0,103; 0,215 dan 0,158.

Tabel 5. Variabel yang dimasukkan dan dikeluarkan dari model regresi

\begin{tabular}{llccc} 
Model & & Beta In & $\mathrm{t}$ & \multicolumn{1}{l}{ Sig. } \\
\hline 1 & kinerja tutor &, $214^{\mathrm{a}}$ & 4,081 &, 000 \\
& kualitas masalah &, $182^{\mathrm{a}}$ & 3,577 &, 000 \\
& perilaku belajar kelompok &, $259^{\mathrm{a}}$ & 4,110 &, 000 \\
\multirow{2}{*}{2} & kinerja tutor &, $169^{\mathrm{b}}$ & 3,172 &, 002 \\
& kualitas masalah &, $145^{\mathrm{b}}$ & 2,850 &, 005 \\
3 & kualitas masalah &, $096^{\mathrm{c}}$ & 1,752 &, 081 \\
\hline
\end{tabular}


Berdasar Tabel 5, maka faktor yang dikeluarkan dari model regresi adalah kualitas masalah oleh karena t hitungnya terkecil $(1,752)$ dengan signifikansi $0,081(\mathrm{p}$ $>0,05)$ dibandingkan dengan variabel yang lain.

Hasil penelitian yang menunjukkan kelima variabel bebas masing-masing memiliki hubungan positif dan signifikan terhadap keefektifan kelompok didukung oleh penelitian-penelitian di bawah ini.

Untuk kinerja tutor, hasil ini didukung oleh penelitian Van Berkel \& Dolmans, ${ }^{14}$ Gijselaers \& Schmidt ${ }^{15}$ yang menyatakan bahwa kinerja tutor yang baik mampu meningkatkan keefektifan kelompok. Hal ini dikarenakan peran tutor dalam proses tutorial sebagai fasilitator yang memberikan fasilitasi dan mengaktifkan kelompok, sehingga memungkinkan kelompok tersebut dapat efektif dalam pencapaian tujuan kelompok. ${ }^{16}$ Peran tutor tersebut akan menjadi lebih baik jika ditunjang oleh pemahaman tutor terhadap pengetahuan, keterampilan dan perilaku dalam memfasilitasi kelompok. Menurut Barrows ${ }^{6}$ keterampilan tutor merupakan tulang punggung dalam tutorial PBL dan tidak ada satupun elemen program dapat berhasil selain meningkatkan kualitas dan kesiapan dari tutor itu sendiri. Moust ${ }^{4}$ menyatakan bahwa cognitive congruence merupakan suatu kondisi penting untuk tutor agar kinerjanya lebih efektif. Cognitive congruence diartikan oleh Schmidt \& Moust ${ }^{4}$ sebagai suatu kemampuan yang dimiliki tutor dalam menjelaskan atau mengekspresikan suatu masalah dengan menggunakan konsep yang sederhana secara mudah dan dimengerti mahasiswa. Dengan kata lain, tutor menjelaskan suatu masalah menggunakan analogi yang mudah dipahami dalam memecahkan kebuntuan dalam mendiskusikan masalah.

Untuk kualitas masalah, hasil ini didukung oleh penelitian Van Berkel \& Dolmans, ${ }^{14}$ Gijselaers \& Schmidt ${ }^{15}$ bahwa kualitas masalah yang baik mampu meningkatkan keefektifan kelompok. Hal ini dikarenakan masalah yang dipaparkan dalam skenario merupakan pemicu proses belajar PBL yang berimplikasi pada pemahaman mahasiswa terhadap materi yang didiskusikan serta merangsang mahasiswa untuk belajar bekerjasama dan aktif. ${ }^{14}$ Dengan kata lain, jika kualitas masalah dalam skenario tidak baik, maka akan menghambat dalam proses belajar, sehingga kelompok tidak dapat memenuhi sasaran belajar yang diharapkan. Menurut
Schmidt \& Moust, ${ }^{6}$ memperbaiki kualitas masalah lebih mudah dibandingkan dengan memper-tahankan kinerja tutor.

Untuk dimensi kepercayaan hubungan antar anggota dalam kelompok, hasil ini didukung oleh penelitian Van den Bossche et al., ${ }^{8}$ bahwa tingginya kepercayaan hubungan antar anggota dalam kelompok akan meningkatkan keefektifan kelompok. Hal ini dimungkinkan karena kepercayaan hubungan tersebut menimbulkan rasa aman untuk menyatakan pendapat, komitmen untuk bertanggung jawab menyelesaikan tugas dalam kelompok, dan spirit kelompok yang mendorong anggota untuk peduli terhadap keberhasilan kelompoknya, oleh karena pada dasarnya anggota kelompok menginginkan semuanya dapat sukses dalam kelompok tersebut.

Untuk perilaku belajar kelompok, hasil ini didukung oleh penelitian Van den Bossche et al. ${ }^{8}$ bahwa perilaku belajar kelompok yang baik mampu meningkatkan keefektifan kelompok. Hal ini dikarenakan perilaku belajar kelompok dapat membangun proses sosiokognitif, yaitu proses saling berbagi kognisi dengan saling bertukar informasi (mutually shared cognition) antar anggota. Proses yang baik akan menimbulkan konflik konstruktif. Konflik konstruktif mengarahkan pada peningkatan hubungan, sehingga hubungan akan menjadi erat yang akhirnya setiap anggota kelompok merasa memiliki tanggung jawab kepada kelompoknya, ${ }^{8,17}$

Untuk motivasi, hasil ini sejalan dengan penelitian Dolmans et al. ${ }^{7}$ Das Carlo et al..$^{18}$ bahwa motivasi yang tinggi mampu meningkatkan keefektifan kelompok. Hal ini dikarenakan motivasi dapat mendorong seseorang dalam kelompok untuk melakukan usaha agar mencapai sasaran belajar secara maksimal. Dorongan tersebut menimbulkan interaksi antar anggota kelompok. Interaksi timbul oleh karena masing-masing anggota memiliki keyakinan bahwa mereka dapat mencapai sasaran belajar secara maksimal jika usaha dilakukan secara bersama-sama. Dengan kata lain, masing-masing anggota kelompok hanya dapat mencapai tujuan pribadi jika kelompoknya sukses. ${ }^{7,19,20}$ Hasil regresi berganda menunjukkan bahwa kinerja tutor, dimensi kepercayaan hubungan antar anggota dalam kelompok, dan dimensi perilaku belajar kelompok merupakan variabel prediktor yang mampu memprediksi keefektifan suatu kelompok $(r=0,739, p<0,05)$. Ketiga variabel ini secara bersamasama memberikan sumbangan efektif terhadap 
keefektifan kelompok sebesar 54\% dengan nilai $\mathrm{F}$ sebesar 87,857 , sedangkan $46 \%$ dipengaruhi oleh variabel lainnya (jumlah orang dalam satu kelompok, jalur komunikasi antara peserta diskusi, jumlah waktu pelaksanaan modul, karakteristik mahasiswa, gaya tutor, tema blok/modul, tingkatan pengetahuan mahasiswa serta sarana dan prasarana penunjang. ${ }^{6,21,22,23,24}$ Dengan demikian, keefektifan kelompok lebih besar dipengaruhi oleh ketiga variabel ini, bukan variabel lain. Hasil tersebut mempunyai arti bahwa pengaruh dari ketiga variabel bebas secara bersama-sama dapat meningkatkan variabel terikat. Adanya kinerja tutor yang baik dan meningkatnya kepercayaan hubungan antar anggota dalam kelompok serta perilaku belajar kelompok akan meningkatkan keefektifan kelompok. Hal ini wajar saja terjadi, karena dilihat dari besarnya koefisien korelasi antar variabel menunjukkan tingkat korelasi sedang $(\mathrm{r}$ $=0,456)$ sampai kuat $(r=0,631)$ dengan tingkat signifikansi $\mathrm{p}<0,05$ dan $\mathrm{p}<0,01$ (Tabel 2).

Kemampuan prediksi ini tidak terlepas dari peran ketiga variabel dalam tutorial PBL. Kinerja tutor merupakan tulang punggung dalam tutorial PBL. Artinya, tutor mempunyai peran dalam mengkompensasi kekurangan yang ada pada skenario maupun proses diskusi melalui penguasaan materi diskusi yang baik maupun keterampilan dalam memfasilitasi kelompok. ${ }^{6}$ Apa yang terjadi dengan? Variabel motivasi dan kualitas masalah pada penelitian ini, tidak masuk dalam model regresi karena keduanya memiliki tingkat korelasi yang rendah sampai sangat rendah. Ada beberapa kemungkinan hal ini bisa terjadi, yaitu: pertama, penggunaan skenario yang sama pada tiap pelaksanaan modul atau perubahan minimal skenario tanpa mengubah masalah dapat menyebabkan mahasiswa tidak dapat maksimal menggali keingintahuan terhadap masalah, sehingga usaha untuk mengkolaborasi pengetahuan yang mereka miliki dengan saling bertukar informasi menjadi berkurang dan menimbulkan rendahnya motivasi untuk belajar yang mengakibatkan diskusi menjadi tidak baik. Hal yang nampak pada mahasiswa adalah kecenderungan mereka untuk memindahkan hasil diskusi kakak tingkat mereka. Dalam kondisi seperti ini, tutor memegang kendali terhadap proses diskusi mereka. Menurut Hunt ${ }^{6}$ persepsi keingintahuan terhadap pengetahuan yang sudah dan belum mereka mengerti akan mendorong motivasi intrinsik untuk belajar. Kedua, adanya efek halo dalam proses evaluasi aspek-aspek kurikulum PBL, yaitu mahasiswa mungkin mengalami kesulitan untuk menilai aspek tersebut secara terpisah satu sama lain yang akan memberikan persepsi yang tidak utuh dari suatu sistem (Gjselaers \& Schmidt dalam Nieminen et $a^{25}$ ). Ketiga, masih belum optimalnya institusi dalam menciptakan lingkungan yang menunjang proses belajar mengajar.

Namun demikian, secara teoretik kualitas skenario dan motivasi mempunyai hubungan dengan keefektifan kelompok. ${ }^{14,15}$ Kualitas masalah dalam skenario mempunyai peran dalam memicu proses diskusi ${ }^{6}$, sedangkan motivasi mempunyai peran dalam membangkitkan seseorang untuk menjelaskan sesuatu yang membuat seseorang tetap bergerak dan membantu orang menyelesaikan tugasnya (Pintrich \& Schunk dalam Pintrich ${ }^{26}$.

\section{KESIMPULAN}

1. Ada hubungan yang positif dan signifikan antara kinerja tutor, kualitas masalah, dimensi kepercayaan hubungan antar anggota dalam kelompok, dimensi perilaku belajar kelompok, dan motivasi dengan keefektifan kelompok. Hal ini berarti semakin tinggi/baik kinerja tutor, kualitas masalah, dimensi kepercayaan hubungan antar anggota dalam kelompok, dimensi perilaku belajar kelompok, dan motivasi, semakin tinggi keefektifan kelompok.

2. Secara bersama-sama, ada hubungan yang positif dan signifikan antara kinerja tutor, dimensi kepercayaan hubungan antar anggota dalam kelompok, dan dimensi perilaku belajar kelompok dengan keefektifan kelompok. Hal ini berarti kinerja tutor, dimensi kepercayaan hubungan antar anggota dalam kelompok, dan dimensi perilaku belajar kelompok, secara bersama-sama merupakan prediktor bagi keefektifan kelompok, sedangkan motivasi dan kualitas masalah bukan merupakan prediktor terhadap keefektifan kelompok.

\section{SARAN}

Implikasi dari penelitian ini bagi pengelola fakultas adalah memberikan perhatian yang serius dalam mengelola faktor-faktor yang mempengaruhi keefektifan kelompok tutorial PBL. Perhatian yang dapat dilakukan adalah membuat program-program atau kebijakan yang bertujuan meningkatkan faktor-faktor tersebut, yang nantinya akan memberikan efek positif terhadap kinerja 
kelompok tutorial. Tutor perlu memberikan perhatian terhadap proses sosiokognitif yang terjadi selama tutorial dengan meningkatkan pemahaman peran tutor terhadap keefektifan kelompok melalui pelatihan-pelatihan tutor, baik didalam maupun diluar institusi, sehingga akan memberikan efek positif terhadap kinerja tutor.

Bagi peneliti selanjutnya, disarankan agar mengikutsertakan variabel-variabel yang lain yang diduga mampu memberikan kontribusi terhadap keefektifan kelompok. Variabel-variabel tersebut diantaranya adalah jumlah orang dalam satu kelompok, jalur komunikasi antar peserta diskusi, jumlah waktu pelaksanaan modul, karakteristik mahasiswa, gaya tutor, tema blok/modul, tingkatan pengetahuan mahasiswa serta sarana dan prasarana penunjang. Selain itu, peneliti selanjutnya bisa menempatkan variabel keefektifan kelompok sebagai variabel yang mempengaruhi prestasi akademik dan mengikutsertakan persepsi tutor tentang keefektifan kelompok yang mereka fasilitasi selama tutorial berlangsung.

Menurut Dolmans \& Schmidt, ${ }^{19}$ metode yang baik untuk mendapatkan pengertian mendalam tentang bentuk belajar kelompok PBL adalah dengan menggunakan berbagai macam metode dan strategi serta pengumpulan data dari berbagai instrumen yang berbeda (triangulate data). Keyton ${ }^{27}$ menyarankan pendekatan kualitatif terseleksi yang akan lebih mampu menghantarkan lebih mendalam sebab-sebab hubungan tersebut dapat berkembang dalam konteks kelompok.

\section{UCAPAN TERIMAKASIH}

Kami menyampaikan terimakasih kepada mahasiswa FK Unissula angkatan 2008, yang telah bersedia menjadi subjek penelitian ini. Ucapan terimakasih juga peneliti sampaikan kepada Dekan Fakultas Kedokteran Unissula dan Tim Modul Penyakit Tropis yang telah memberi ijin kepada peneliti untuk mengambil data.

\section{DAFTAR PUSTAKA}

1. Crosby J. Learning in small groups. Med Teach.1996;18(3):189-202.

2. Wood DF. Problem based learning. BMJ. 2003;326(7384):328-30.

3. Van Berkel HJM, Schmidt HG. Motivation to commit oneself as a determinant of achievement in problembased learning. High Educ. 2000; 40:231-42.
4. Schmidt HG, Moust JHC. What makes a tutor effective? A structural-equations modelling approach to learning in problem-based curricula. Acad Med. 1995;70:708-14.

5. Schmidt HG, Dolmans DHJM, Gijselaers WH, Des Marchais JE.. Theory-guided design of a rating-scale for course evaluation in problem-based curricula. Teach Learn Med. 1995;7:82-91.

6. Schmidt HG, Moust JHC. Factors affecting small-group tutorial learning: A review of research. In: Evensen DH, Hmelo CE, editors. Problem-based learning: a research perspective on learning interactions. New York (NY): Lawrence Erlbaum; 2000:19-52.

7. Dolmans DHJM, Wolfhagen HAP, Van der Vleuten CPM. Motivational and cognitive processes influencing tutorial groups. Acad Med. 1998;73(10):22-4.

8. Van den Bossche P, Segers M, Kirschner PA. Social and cognitive factors driving teamwork in collaborative learning environments team learning beliefs and behaviors. Small Group Research. 2006;37(5):490521.

9. Dolmans DHJM, Ginns P. A short questionnaire to evaluate the effectiveness of tutors in PBL: validity and reliability. Med Teach. 2005;27(6):534-8.

10. Munshi FM, El Zayat ESA, Dolmans DHJM. Development and utility of a questionnaire to evaluate the quality of PBL problems. South East Asian Journal of Medical Education. 2008;2(2):32-40.

11. Lepper MR, Corpus JH, dan Iyengar SS. Intrinsic and extrinsic motivational orientations in the classroom: age differences and academic correlates. Journal of Educational Psychology. 2005;97 (2):184-96.

12. Sugiyono. Statistika untuk penelitian. Bandung: Alfabeta; 2009.

13. Santoso S. Mengatasi berbagai masalah statistik dengan SPSS versi 11.5. Jakarta: PT Elex Media Komputindo; 2003.

14. Van Berkel HJM, Dolmans DHJM. The influence of tutoring competencies on problems, group functioning and student achievement in problem based learning. Med Ed. 2006; 40:730-6.

15. Gijselaers WH, Schmidt HG. Towards a causal model of student learning within the context of a problembased curriculum. In: Nooman ZN, Schmidt HG, \& Ezzat ES, editors. Innovation in medical education. An evaluation of its present status. New York (NY): Springer Publishing; 1990.

16. Harsono. Pengantar problem based learning. Yogyakarta: Medika Fakultas Kedokteran UGM; 2005.

17. Walgito B. Psikologi kelompok. Yogyakarta: Andi; 2007.

18. Das Carlo M, Swadi H, Mpofu D. Medical student perceptions of factors affecting productivity of problem- 
based learning tutorial groups: does culture influence the outcome?. Teaching and Learning in Medicine. 2003; 15(1):59-64.

19. Dolmans DHJM, Schmidt HG. What do we know about cognitive and motivational effects of small group tutorials in problem-based learning?. Advances in Health Sciences Education. 2006;11:321-6.

20. Santrock JW. Psikologi Pendidikan. Jakarta: Salemba Humanika; 2009.

21. Groves M, Régo P, O’Rourke P. Tutoring in problembased learning medical curricula: the influence of tutor background and style on effectiveness. BMC Med Ed. 2005, 5:20

22. Sarwono SW, Meinarno EA. Psikologi sosial. Jakarta: Salemba Humanika; 2009.

23. Wheelan S. Group size, group development, and group productivity. Small Group Research. 2009; 40; 247.
24. Zanolli MB, Boshuizen HPA, De Grave WS. Students' and tutors' perceptions of problems in PBL tutorial groups at a Brazilian Medical School. Education for Health. 2002;15(2):189-201.

25. Nieminen J, Sauri P, Lonka K. On the relationship between group functioning and study succes in problem based learning. Med Ed 2006;40:64-71.

26. Pintrich P. Motivation and classroom learning. In: William M. Reynolds, Gloria E, Miller, Weiner IB, editors. handbook of psychology: educational psychology. New Jersey: John Willey \& Son, Inc; 2003.

27. Keyton J. The relational side of groups. Small Group Research. 2000;31:387-96. 